\section{Standardization of lyophilization medium for Streptococcus thermophilus subjected to viability escalation on freeze drying}

\author{
Rohit Sharma, ${ }^{1,2}$ Bhagwan S. Sanodiya, ${ }^{1}$ \\ Gulab S. Thakur, ${ }^{1}$ Pallavi Jaiswal, ${ }^{1}$ \\ Anjana Sharma, ${ }^{2}$ Prakash S. Bisen ${ }^{1,2}$ \\ 1Microbial Biotechnology Laboratory, \\ Tropilite Foods Pvt. Ltd., Davars Campus, \\ Gwalior; ${ }^{2}$ Department of Post Graduate \\ Studies and Research in Biological \\ Sciences, Rani Durgavati \\ Vishwavidyalaya, Jabalpur, India
}

\section{Abstract}

The objective of the present study is to develop a lyophilization medium for Streptococcus thermophilus (NCIM 2904) as the industrial exploitation of this bacterium totally depends upon preservation and lyophilization protocols. Protective effect of 18 compounds were observed individually and in combinations with different sugars, sugar alcohols, polymers, protein concentrates and buffers. Among all the protectants tested, ammonium citrate $(1 \% \mathrm{w} / \mathrm{w}), \mathrm{K}_{2} \mathrm{HPO}_{4}(1 \%$ $\mathrm{w} / \mathrm{w})$ and $\mathrm{KH}_{2} \mathrm{PO}_{4}(1 \% \mathrm{w} / \mathrm{w})$ provided lowest protection to these bacterial cells while $10 \%$ (w/w) sodium caseinate, whey protein concentrate, sweet whey powder, and skim milk showed significant results in viability escalation. Survival in carbon sources like lactose, sucrose and maltodextrine was also favored maximally. Combination of sodium caseinate $10 \%$, skim milk $5 \%$, sucrose $5 \%$, lactose $5 \%$ and mono sodium glutamate $1 \%$ in distilled water in ratio of 1:5 with $S$. thermophilus showed survival percentage of $96 \%$.

\section{Introduction}

Starter cultures for fermented foods are today developed specifically with high cell viability and adequate shelf life. Industrialization and market competition among these products generates a need for better and efficient starter. Lactic acid bacteria are commonly used as starters for food fermentation with Streptococcus thermophilus playing a central role in most of the fermented food products like curd, yogurt, kefir, cheese etc. Freeze drying technique is a dehydrating method in which biological materials are first frozen followed by sublimation (primary drying) and desorption (secondary drying), generally used for long term preservation of lactic acid bacteria starters, but freeze drying also brings changes in physical state of membrane lipids and structure of sensitive proteins leading to viability issues. ${ }^{1}$ However, demand of starter in modern era, continuously expanding the interest to create ready to use lyophilized starter with improved stress and shock tolerance. ${ }^{2}$ Consequently, some compounds such as polyols, polysaccharides, disaccharides, amino acids, proteins, vitamins, and various salts have been examined for their potential role to improve the survival of LAB throughout freeze drying process. ${ }^{3}$ Use of $S$. thermophilus as starter culture for curd, depends on the concentration and preservation technologies employed, which are required to guarantee long-term delivery of stable cultures in terms of viability and functional activity.

The choice of an appropriate growth medium is therefore of fundamental importance to increase the survival of organisms during and after drying, ${ }^{4,5}$ as compatible solutes are probably accumulated intra-cellularly. ${ }^{6}$ Sucrose and monosodium glutamate (MSG) have positive effects during storage of various dried LAB.,7 The degree of protection during storage accorded by a given additive, however, was demonstrated to be species and strain dependent. Nevertheless, freeze-drying can lead to denaturation of sensitive proteins which will decrease the viability and activity of the cell. Lyophilization brings two different kinds of stress on bacteria. In freezing stage the cells undergo through cold shock which may change the physical state of the membrane lipids undergoing a phase of transition which may odedwise rupture the cell wall. These negative effects are commonly protected by addition of some protective agents with the bacteria prior to lyophilization. The aim of the study is to design a protective lyophilization medium for Streptococcus thermophilus (NCIM 2904) basically a specialized yogurt strain. The efficacy and potential of these protective agents will also be tested on the basis of escalation in viability of the cells.

\section{Materials and Methods}

\section{Microorganism}

Streptococcus thermophilus NCIM 2904 was obtained from National Collection of Industrial Microorganisms, NCL, Pune, India.

\section{Sample preparation}

The organisms were grown in MRS broth (Merck) at $37^{\circ} \mathrm{C}$ with incubation period of 24 hours. The turbid broth samples were then centrifuged at 6000 RPM for 10 minutes fol-
Correspondence: Rohit Sharma, Microbia Biotechnology Laboratory, Tropilite Foods Pvt. Ltd., Davars Campus, Tansen Road, Gwalior 474002, MP, India.

Tel.: + 91.751.4056355

E-mail: accessrohit25@gmail.com

Key words: lyophilization, freeze drying, S. thermophilus, lyoprotectant, viability.

Contributions: RS, BSS, were involved in experimental work; GST, PJ, were associated with analyses of the study, writing first draft of the manuscript; AS, PSB, were associated with study design, execution and manuscript writing.

Conflict of interests: the authors declare no potential conflict of interests.

Received for publication: 25 March 2014.

Revision received: 4 August 2014.

Accepted for publication: 4 August 2014.

This work is licensed under a Creative Commons Attribution NonCommercial 3.0 License (CC BYNC 3.0).

(C) Copyright R. Sharma et al., 2013

Licensee PAGEPress, Italy

Microbiology Research 2014; 5:5402

doi:10.4081/mr.2014.5402

lowed by pellet washing with physiological $\mathrm{NaCl}(0.9 \%)$ solution. The pellet were resuspended in $10 \%$ sterile solution of defatted skim milk powder (Himedia, India) and then distributed in sterile vials of $1 \mathrm{~mL}$ quantity followed by immediate freezing at $-80^{\circ} \mathrm{C}$ for further use.

\section{Lyophilization medium}

The following compounds were used to check the viability improvement.

Sugars: Lactose, monohydrate (min 99.5\%, milk sugar, Himedia, India), Sucrose, Extra pure (min 99.5\%, Himedia, India), D-(-)Fructose, Extra pure (min 99\%, Himedia, India), D-(+)-Glucose monohydrate (min 99.5\%, Himedia, India), D-(-)-Mannitol, Extra pure (min 99\%, Himedia, India), D-(-)-Sorbitol (min 99\%, Himedia, India), D-(+)-Maltose monohydrate (min 95\%, Himedia, India), Maltodextrine (Himedia, India), D-(-)-Ribose (Min 99\%, Himedia, India), D-(-)-Arabinose (Min 99\%, Himedia, India).

Polymers, inorganic compounds and other media: distilled water, Monosodium-L-glutamate monohydrate (min $98 \%$, Himedia, India), meso-Inositol (min 98\%, Himedia, India), glycerol, purified (min 99\%, Himedia, India), sodium chloride, extra pure (min 99\%, Himedia, India), Skim Milk powder, defatted (Himedia, India), di-Potassium hydrogen phosphate (min 99\%, Himedia, India), Potassium dihydrogen orthophosphate, purified (min 99\%, Himedia, 
India), tri-ammonium citrate, extra pure (min $97 \%$, Himedia, India), whey protein concentrate (Fonterra, New Zealand), sweet whey powder (Fonterra, New Zealand), sodium caseinate (Arla Foods, Denmark).

\section{Effect of lyoprotectant and lyopro- tectant formulations on viability}

\section{of $S$. thermophilus}

Different lyoprotectant combinations were prepared to check the cell viability after lyophilization. A total of 18 lyoprotectants were used to develop 40 combinations for evaluating viability results and escalation. All the lyoprotectants $(10 \% \mathrm{w} / \mathrm{w})$ were prepared and sterilized except monosodium glutamate $(1 \% \mathrm{w} / \mathrm{w})$, meso-inositol $(0.5 \% \mathrm{w} / \mathrm{w}), \mathrm{KH}_{2} \mathrm{PO}_{4}(1 \% \mathrm{w} / \mathrm{w})$, $\mathrm{K}_{2} \mathrm{HPO}_{4}(1 \% \mathrm{w} / \mathrm{w})$, ammonium citrate $(1 \% \mathrm{w} / \mathrm{w})$ which were sterilized with mentioned $\mathrm{w} / \mathrm{w}$. These protectants in single and in combinations were mixed with freezed vials in 1:5 ratios ( $1 \mathrm{~mL}$ inocolum vial and $5 \mathrm{~mL}$ lyoprotec$\operatorname{tant}$ ). Lyophilization of the samples was done at 0.04 mbar vacuum at $-50^{\circ} \mathrm{C}$ (Alpha $1-2, \mathrm{LO}$ plus, Martin Christ).

\section{Results and Discussion}

\section{Effects on viability with different lyoprotectant}

All the compounds used as lyoprotectants in this study were found to be effective in most of the cases, providing protection to various lactic acid bacteria. ${ }^{8}$ All the 18 lyoprotectants were used separately as medium to provide protection from high vacuum and freeze shock during lyophilization along with a blank sample. Skim milk powder was used for sample preparation before freezing because of its property of preventing cellular injury by stabilizing the cell membrane constituents and creating a porous structure in the freeze dried prod- uct. ${ }^{9,10}$ Skim Milk also contains proteins that provide a coating to the bacterial cells. ${ }^{11}$ On testing the viability of $S$. thermophilus with skim milk ( $10 \% \mathrm{w} / \mathrm{w})$ shows highest cell viability of $74 \%$ when observed in dry form. On the other hand sugar and sugar derivatives were also used for their protective effect during lyophilization and also during after lyophilization storage. ${ }^{7,12}$ Sugar alcohol like sorbitol has found to be one of the strong protective agent during lyophilization and storage of $L$. bulgaricus, L. plantarum, L. rhamnosus, E. faecalis and $E$. durans, ${ }^{12}$ but in current study, its performance as protective agent for lyophilization of S.thermophilus was observed dull and discouraging. In fact, cheaper sugar sources like sucrose $(72 \%)$, glucose $(51 \%)$, lactose $(66 \%)$ and maltodextrine $(67 \%)$ showed better

$A$
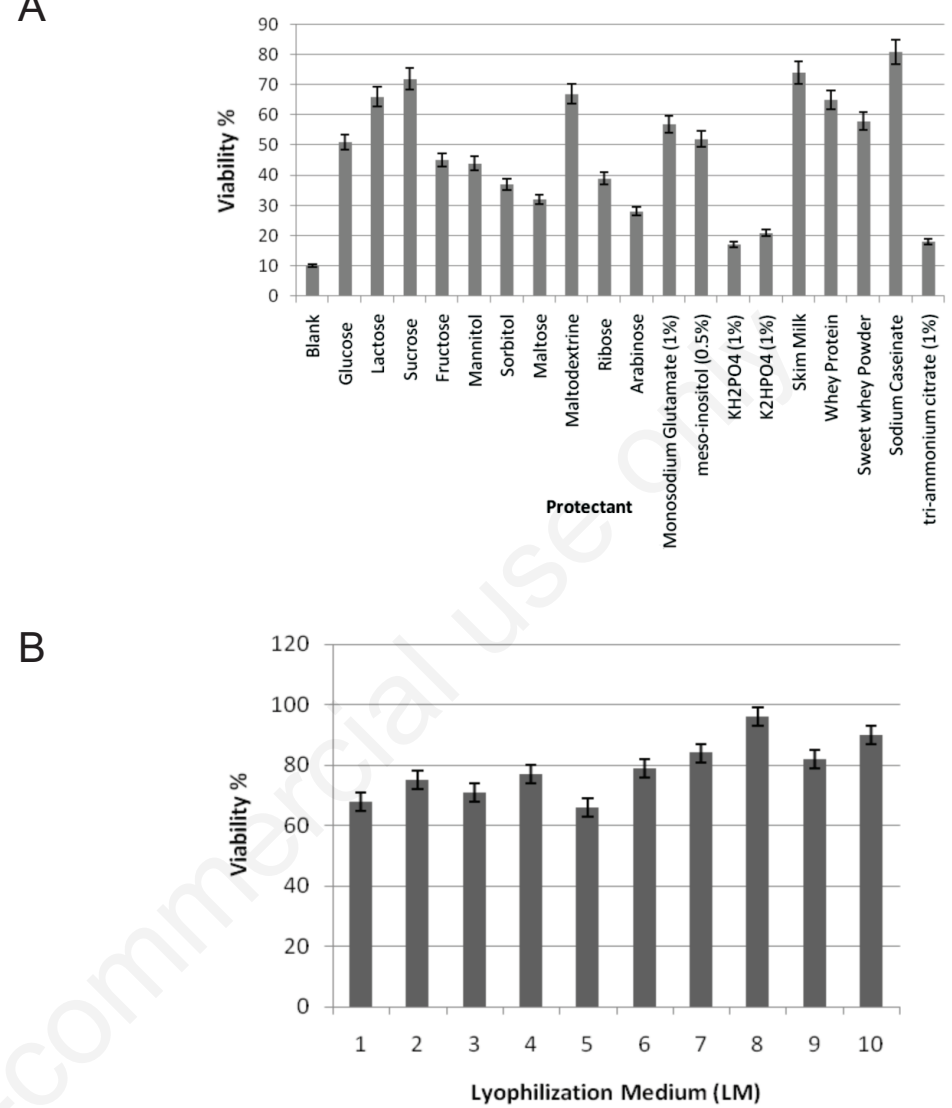

Figure 1. A) Effect of different lyoprotectants (A) and different lyophilization media (B) on the viability after lyophilization. If not indicated $10 \%(\mathrm{w} / \mathrm{w})$ solution were used. The error bars show the standard deviation

Table 1. Combinations of protectants along with the ratio of addition.

\begin{tabular}{llc}
\hline Lyophilivation medium & Constituents in percentage & Proportion of addition* \\
1 & Skim Milk 10\%, Sucrose 5\%, Sodium Caseinate 5\% & $1: 5$ \\
2 & Skim Milk 10\%, Lactose 5\%, Whey Protein Concentrate 5\% & $1: 7$ \\
\hline 3 & Skim Milk 10\%, Maltodextrine 5\%, Sweet whey Powder 5\% & $1: 5$ \\
4 & Sodium Caseinate 10\%, Skim Milk 5\%, Maltodextrine 5\%, Mono sodium glutamate 1\% & $1: 8$ \\
\hline 5 & Sodium Caseinate 5\%, Whey Protein concentrate 5\% & $1: 8$ \\
& Maltodextrine 10\%, Meso-inositol 0.5\%, Mono sodium glutamate 1\% & $1: 5$ \\
\hline 7 & Sodium Caseinate 5\%, Lactose 5\%, Mono sodium glutamate 1\%, Skim Milk 5\% & $1: 5$ \\
\hline 9 & Sodium Caseinate 10\%, Skim Milk 5\%, Sucrose 5\% & $1: 5$ \\
10 & Mono sodium glutamate 1\% & $1: 5$ \\
\hline
\end{tabular}

*mL of cell inocolum:protective medium. 
results (Figure 1A) compared to high cost sugars like mannitol (44\%), fructose (45\%), maltose (32\%), ribose (39\%) and arabinose (28\%) as high cost compounds would likely to restrict their large scale industrial use.

The ability of mono sodium glutamate (MSG) to protect microbial cells during lyophilization and cryopreservation is also described by a number of researchers. ${ }^{13,14}$ Use of $1 \%(\mathrm{w} / \mathrm{w})$ MSG for $S$. thermophilus also showed protective effects with $57 \%$ viability, while as more than $1 \%$ quantity showed viability loss. The effect of $\mathrm{K}_{2} \mathrm{HPO}_{4}$ and $\mathrm{KH}_{2} \mathrm{PO}_{4}$ on cell viability of $B$. bifidum has recently been studied by Qin et al. ${ }^{15}$ showing cell survival viability up to $77.80 \%$ with $\mathrm{KH}_{2} \mathrm{PO}_{4}$ and $79.82 \%$ with $\mathrm{K}_{2} \mathrm{HPO}_{4}$. But studying the effect of these compounds on $S$. thermophilus reveals opposite results with $\mathrm{K}_{2} \mathrm{HPO}_{4}(1 \% \mathrm{w} / \mathrm{w}) 21 \%$ and $\mathrm{KH}_{2} \mathrm{PO}_{4}(1 \% \mathrm{w} / \mathrm{w}) 17 \%$ only. Milk proteins present in skim milk leads to stabilization of protein structures via reactions between the amino group of the microbial cell proteins and with protectant. Other mixtures with casein protein and whey proteins were also tested which reveals interesting results by providing high cell viability to $S$. thermophilus. Sodium caseinate resulted in highest viability of $81 \%$ while as whey protein concentrate (WPC) with $65 \%$ and sweet whey powder (SWP) 58\% (Figure 1B).

\section{Effects on viability with different lyoprotectant medium}

A total of 40 combinations were prepared based on the results of the individual protectant role in providing the viability to $S$. thermophilus on lyophilization. After initial studies combinations producing more than $50 \%$ viability were considered for further studies in which only 10 combinations were observed significant with of high viability (Table 1). The ratio of addition was also studied and implemented on the basis of thickness and viscosity of the prepared lyophilization medium. Lyophilization medium (LM) 6, 7, 8 and 10 were found efficient in maintaining the cell viability both during freezing and drying state of lyophilization. LM 8 was observed as unique viability escalator providing better results compared to other lyophilization media. The reason behind the success of LM 8 is the role of protective milk proteins which are in abundance in this particular formulation playing a role in stabilizing the protein structures of this microbe and sugar source playing a crucial part in maintaining the physical state of the membrane lipids and enzyme level. All the protective compounds in lyophilization medium 8 have their unique role in maintaining the cell viability, also the medium is cost efficient and can easily be implemented on large scale industrial production of $S$. thermophilus for its role in starter culture. Protocols for the prepa- ration of freeze dried lactic acid bacteria vary widely between strain and species. A lyophilization medium may not produce expected positive results if proper protocol for down-streaming was not followed.

\section{Storage viability results}

Studies on lyophilization of lactic acid bacteria suggest that the stability of lyophilized cells decreases during storage which also happened to our current subject of study stored at $-8^{\circ} \mathrm{C}$. Up to $5 \%$ viability loss was observed on reexamining the stored vials of S.thermophilus after a period of 180 days. On the other hand lyophilized vials of the same microbe stored at $-60^{\circ} \mathrm{C}$ showed higher survival rates with less than $1 \%$ viability loss. An organism which survives the various steps of freezing, drying and storage may, nevertheless, lose its viability during rehydration. Therefore, rehydration is a critical step in the recovery of freeze-dried microorganisms, because cells that were subjected to sub lethal injury may not be able to repair said damage if they are rehydrated under inappropriate conditions.

\section{Conclusions}

S. thermophilus is one of the most important dairy cultures worldwide for its use as starter and metabolic end products escalating a need for its economical handling with maximum output. Current study concludes development of an economic cryoprotectant using commercially viable sources of protein and sugar. A combination of sodium caseinate, skim milk, sucrose and mono sodium glutamate was tested on Streptococcus thermophilus NCIM 2904 as cryoprotectant resulting in higher viability on freeze drying.

\section{Future prospects}

These combinations will be studied further for viability and cell loss on other lactic acid bacteria.

\section{References}

1. Leslie SB, Israeli E, Lighthart B, et al. Trehalose and sucrose protect both membranes and proteins in intact bacteria during drying. Appl Environ Microbial 1995;61:3592-97.

2. Broadbent JR, Lin C. Effect of heat shock or cold shock treatment on the resistance of Lactococcus lactis to freezing and lyophilization. Cryobiol 1999;39:88-102

3. Champagne CP, Gardner N, Brochu E, et al. the freeze-drying of lactic acid bacteria, a review. Can Inst Food Sci Technol J 1991;24:118-28.

4. Welsh DT. Ecological significance of compatible solute accumulation by microorganisms: from single cells to global climate. FEMS Microbiol Rev 2000;24:263-90.

5. Silva J, Carvalho AS, Pereira $\mathrm{H}$, et al. Induction of stress tolerance in Lactobacillus delbrueckii ssp. bulgaricus by the addition of sucrose to the growth medium. J Dairy Res 2004;71:121-5.

6. Linders LJM, Meedink G, Vant Riet K. Effect of growth parameters on the residual activity of L. plantarum after drying. $\mathrm{J}$ Appl Microbiol 1997;82:683-8.

7. Carvalho AS, Silva J, Ho P, et al. Effect of additives on survival of freeze-dried Lactobacillus plantarum and Lactobacillus rhamnosus during storage. Biotechnol Lett 2002;24:1587-91.

8. Carvalho AS, Silva J, Ho P, et al. Effects of various sugars added to the growth media upon thermotolerance and survival throughout storage of freeze-dried Lactobacillus delbrueckii ssp. bulgaricus. Biotechnol Lett 2004;20:248-54.

9. Castro HP, Teixeira PM, Kirby R. Changes in the membrane of Lactobacillus bulgaricus during storage following freeze-drying. Biotechnol Lett 1996;18:99-104.

10. Selmer-Olsen E, Birkeland SE, Srhaug T. Effect of protective solutes on leakage from and survival of immobilized Lactobacillus subjected to drying, storage and rehydration. J Appl Microbiol 1999;87: 429-37.

11. Abadias M, Banabarre A, Teixido N, et al. Effect of freeze-drying and protectants on viability of the biocontrol yeast Candida sake. Int J Food Microbiol 2001;65:173-82.

12. Carvalho AS, Silva J, Ho P, et al. Protective effect of sorbitol and monosodium glutamate during storage of freeze-dried lactic acid bacteria. Le Lait 2003;83:203-10.

13. Font de Valdez G, de Giori G, de Ruiz Holgado AP, et al. Protective effect of adonitol on lactic acid bacteria subjected to freeze-drying. Appl Environ Microbiol 1983;45:302-4.

14. Martos GI, Ruiz-Holgado AP, Olivier G, et al. Use of conductimetry to evaluate Lactobacillus delbrueckii ssp. bulgaricus subjected to freeze-drying. Milchwissenschaft 1999;54:128-30

15. Qin T, Ma Q, Chen H, Shu GW. Effect of $\mathrm{MgSO} 4, \mathrm{NaHCO3,} \mathrm{KH2P04,} \mathrm{K2HPO4} \mathrm{and}$ ascorbic acid on survival of Bifidobacterium bifidum during freezedrying. Adv Material Res 2013;675:346-49. 